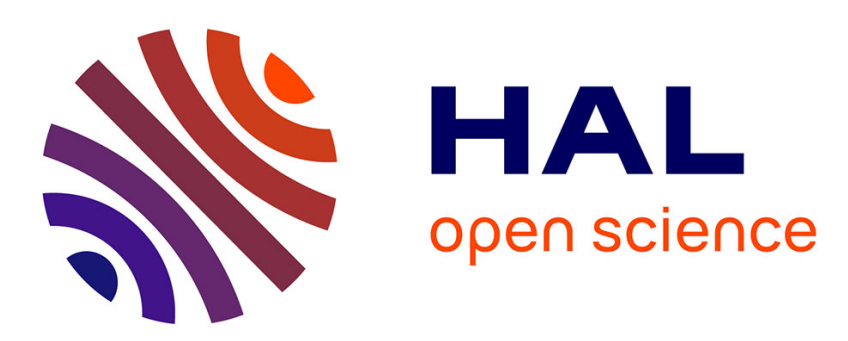

\title{
Spatial distribution of weed diversity within a cereal field
}

J. Izquierdo, J. M. Blanco-Moreno, L. Chamorro, J. L. González-Andújar, F. X. Sans

\section{- To cite this version:}

J. Izquierdo, J. M. Blanco-Moreno, L. Chamorro, J. L. González-Andújar, F. X. Sans. Spatial distribution of weed diversity within a cereal field. Agronomy for Sustainable Development, 2009, 29 (3), $10.1051 /$ agro/2009009 . hal-00886502

\section{HAL Id: hal-00886502 https://hal.science/hal-00886502}

Submitted on 1 Jan 2009

HAL is a multi-disciplinary open access archive for the deposit and dissemination of scientific research documents, whether they are published or not. The documents may come from teaching and research institutions in France or abroad, or from public or private research centers.
L'archive ouverte pluridisciplinaire HAL, est destinée au dépôt et à la diffusion de documents scientifiques de niveau recherche, publiés ou non, émanant des établissements d'enseignement et de recherche français ou étrangers, des laboratoires publics ou privés. 


\title{
Spatial distribution of weed diversity within a cereal field
}

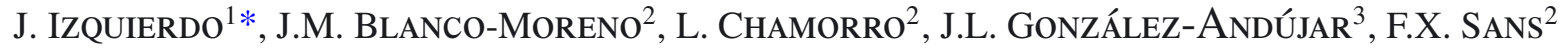 \\ ${ }^{1}$ Departament Enginyeria Agroalimentària i Biotecnología, Universitat Politècnica de Catalunya. Campus del Baix Llobregat, Av. Canal Olímpic s/n, \\ 08860, Castelldefels, Catalunya, Spain \\ ${ }^{2}$ Departament Biologia Vegetal, Universitat de Barcelona, Av. Diagonal 645, 08028 Barcelona, Catalunya, Spain \\ ${ }^{3}$ Departamento Protección de Cultivos, Instituto de Agricultura Sostenible, P.O. Box 4084, 14080 Córdoba, Spain
}

(Accepted 14 April 2009)

\begin{abstract}
Weeds are key components of agroecosystems because they support biological diversity within crop fields. Ecological indicators of weed diversity are usually assessed on a field scale, but weeds are distributed unevenly within fields. Here, we explore spatial distribution of diversity in weed seed banks, and how a failure of grass weed control may affect biodiversity indicators. We studied spatial distribution and stability of species richness, Shannon's diversity index, and Pielou's evenness index of a weed seed bank, site-specifically and for the entire field, over three years in a commercial winter wheat field regularly treated with narrow- and broad-leaved herbicides. 254 soil samples were taken on $10 \mathrm{~m} \times 10 \mathrm{~m}$ grids at the beginning of each season. Seeds were identified by germination in a greenhouse and indices were assessed for each point. The spatial structure of the indices was described by spherical isotropic semivariograms. Our findings show that diversity and evenness computed for the entire field both decreased by $63 \%$ after lack of grass weed control, and increased $32 \%$ and $31 \%$, respectively, the following year. However, richness, diversity and evenness were not homogeneous across the field. Diversity and evenness became increasingly patchy over time, as shown by a spatial dependence increasing by $21 \%$ and $40 \%$, respectively, after two years. This finding is related to the reduction in the patch extension of broad-leaved species due to broad-leaved herbicide application each year and the expansion of grass patches due to the lack of grass control in the first year. Spatial location of patches was not stable over time. Nevertheless, weedy areas remained on the field and represent plant diversity caches that may contribute to maintaining global biodiversity. This information is missed if a single biodiversity index is computed for the entire field. Knowledge of spatial distribution of weed diversity within a field will be useful for identifying wildlife conservation areas and understanding changes in biodiversity in cropland ecosystems better.
\end{abstract}

seedbank / species richness / Shannon diversity index / Pielou evenness index / mapping / herbicides / kriging / nonparametric test / patches.

\section{INTRODUCTION}

Several studies have confirmed the dramatic loss of biodiversity in croplands (Robinson and Sutherland, 2002; Wilson and King, 2003). Some weed control practices have significantly reduced wildlife populations by modifying weed abundance and species assemblages (Chamberlain et al., 2000; Stoate et al., 2002). Weed species extinction (Firbank, 1988) and loss of weed species diversity on a field scale (Andreasen et al., 1996) have been reported. Furthermore, changes in the weed flora of croplands such as shifts from broad-leaved weeds to grasses or changes in the rank order of weed occurrence are well documented (Derksen et al., 1995; Sutcliffe and Kay, 2000; Hyvönen et al., 2003a). This loss of biodiversity causes substantial public and policy concern because weeds have an important ecological function as a key com-

*Corresponding author: jordi.izquierdo@upc.edu ponent of agroecosystems, providing the primary production upon which food chains are built (Marshall et al., 2003). One of the main interests of the European Union is to develop agricultural-management methods that harmonize farm production and the conservation of natural resources through the sustainable management of biodiversity (EEA, 2004).

Ecological indicators such as species richness, Shannon's index and Pielou's evenness have been used to provide information about plant diversity in croplands (Hyvönen et al., 2003b; Murphy et al., 2006). Most of the studies obtained a numerical value for the entire field considering uniform weed composition and relative abundance of weeds throughout the field. However, weed species are distributed unevenly and, consequently, diversity is not expected to be homogeneous within the field. As Podani (2006) pointed out, diversity indices do not reflect structural aspects of communities because community structure is scale-related. Furthermore, biotic or abiotic factors may act site-specifically and promote 
local-scale patterns of change that may differ from the global trend. These local variations in weed populations (increases, reductions or extinctions) may affect competitive interactions between crops and weeds and cannot be described by global indices. Additionally, areas of higher diversity provide habitats for pest enemies, refuges for farmland birds or attract pollinators or dispersal agents (Storkey and Westbury, 2007). Knowledge of the location of such areas is extremely important in biodiversity studies. The evaluation of the spatial structure of weed diversity may help in these issues. Additionally, it will contribute to developing precision agriculture techniques that require site-specific knowledge of the distribution of ecological indicators within the field.

Several studies about plant diversity, considering spatial variability, have been carried out in forest ecosystems (Hernández-Stefanoni and Ponce-Hernández, 2006; Wang et al., 2008), but, to our knowledge, no studies have been conducted on the spatial distribution of diversity in croplands and how this distribution can be affected by changes in weed management. This paper deals with the analysis of the spatial distribution and stability of ecological indicators such as species richness, Shannon's index and Pielou's index of the weed seed bank of a commercial winter wheat field regularly treated with narrow- and broad-leaved herbicides. In croplands, weed seed banks are considered a more reliable estimate of the weediness of an area than seedlings or adults, as they are the primary source of weeds in cultivated soils. We hypothesize that ecological indicators of weed diversity have a spatial distribution in patches and that the failure of grass weed control in a given year can cause rapid changes relating to the increase in grass seeds. Herbicide control in Mediterranean areas frequently fails in a given year due to adverse environmental conditions for herbicide activity (e.g. low temperatures or heavy rains after herbicide spraying). We hypothesize that these changes could be more clearly identified through the spatial analyses of the indicators rather than by single values for the entire field, because of the uneven spatial distribution of weeds in the field.

The following questions are addressed: (1) are there differences in species diversity within a field?; (2) what is the shortterm effect of lack of grass weed control in a given year on the global and spatial distribution of species richness, diversity and evenness?; and (3) what additional information provides the knowledge of spatial distribution of species richness, diversity and evenness with respect to global indices for the entire field?

\section{MATERIALS AND METHODS}

\subsection{Site and experimental design}

A 3-year study was carried out in Calonge de Segarra (North-eastern Spain, 41 45’32” North, 1³1'29” East) from 2001 to 2003, in a commercial winter wheat (Triticum aestivum L., cv. Soissons) field naturally infested with narrowand broad-leaved weeds. The field area was 8 ha with elevation ranges of up to $10 \mathrm{~m}$. Soil texture ranged from loam to clay loam. The field was farmer-managed, with the typical agronomic practices for the region. Seedbeds were prepared with one pass of a harrow before sowing. Wheat was sown at a rate of $180 \mathrm{~kg} \mathrm{ha}^{-1}$ in late October each year. Fertilizer was added twice during each season: a granular application of NPK at 33-49-49 $\mathrm{kg} \mathrm{ha}^{-1}$ was applied before sowing and a liquid application of SN32 (urea-ammonium nitrate) at $90 \mathrm{~kg} \mathrm{~N} \mathrm{ha}^{-1}$ was applied during the winter at the Z13-15 wheat stage. Broad-leaved weeds were controlled with a mixture of herbicides (chlorsulfuron + tribenuron-methyl at $9+$ $9.4 \mathrm{~g}$ a.i. $\mathrm{ha}^{-1}$ ) and grass weeds with diclofop-methyl at $350 \mathrm{~g}$ a.i. $\mathrm{ha}^{-1}$ at the early tillering stage of the crop (Z30) each year. In order to check the effect of a grass weed control failure on weed diversity, there was no treatment against grass weeds the first year.

The intensive field surveys to estimate the weed seed bank were carried out on a $150 \mathrm{~m} \times 150 \mathrm{~m}$ area of the field. Sampling was performed on a $10 \mathrm{~m} \times 10 \mathrm{~m}$ grid pattern resulting in 254 soil sampling units, with two unsampled points lying in the north-eastern corner of the surveyed area. Nodes were georeferenced with a Differential Global Positioning System (DGPS) that allowed for accurate relocation for each year's sampling. Sampling at each point included 4 cores (4.5 $\mathrm{cm}$ in diameter and $10 \mathrm{~cm}$ deep) that represented a surface of $63.6 \mathrm{~cm}^{2}$. Soil samples were collected in January 2001, 2002 and 2003, prior to herbicide application, and emerged seedlings within each core were added to the seed bank counts. Each soil sample was disaggregated and placed in a shallow tray for 6 months on a non-heated greenhouse bench under natural photoperiod and watered regularly. A detailed description of the method is given by Gibson (2002). Emerged seedlings were identified and removed after counting. Nomenclature of species follows Bolòs et al. (2005).

\subsection{Species richness, diversity and evenness of weed seed bank}

Diversity of communities can be broken down into two components, the total number of species (richness), and the contribution of each species to the community structure (evenness). For this reason, the following parameters were calculated for each sampling point, each year (Magurran, 2004):

(1) Species richness, $S$. We used the number of species per sample as an indicator of species richness;

(2) Shannon's diversity index, $H^{\prime}$. It was calculated as:

$$
H^{\prime}=-\sum_{i=1}^{S} p_{i} \ln p_{i}
$$

where $S$ is the total number of species and $p_{i}$ is the proportion of individuals of species $i$ in the seed bank relative to the total number of individuals of all species. $H^{\prime}$ is maximum when all $\mathrm{S}$ species are represented by the same number of individuals, that is, a perfectly even distribution of abundances. $H^{\prime}$ is 0 if there is only one species in the sample. 
(3) Pielou's evenness index, $J^{\prime}$. It was calculated by dividing $H^{\prime}$ by $H_{\max }\left(\right.$ here $H_{\max }=\ln S$ ):

$$
J^{\prime}=H^{\prime}(\ln S)^{-1}
$$

Evenness values can range between 0 and 1: a value of 0 corresponds to a community of one species (total dominance or no diversity), and a value of 1 to a community where all species are equally abundant.

Seed counts from the 254 sampling units were aggregated in order to compute the species richness, diversity and evenness for the entire field each year.

\subsection{Spatial variation in species richness, diversity and evenness of seed bank}

Spatial variation in species richness, diversity and evenness was analyzed using semivariograms. The semivariogram characterizes the average degree of variability between the samples as a function of separation distance and direction. The combination of a lag spacing of $10 \mathrm{~m}$ and a lag tolerance of $3 \mathrm{~m}$ over an extent of $100 \mathrm{~m}$ in general produced the clearest experimental semivariograms with a sufficient number of data pairs to estimate the empirical semivariogram confidently. Experimental semivariograms were calculated first in two directions (north-south and east-west) with an angular tolerance of $22.5^{\circ}$ to determine whether the semivariance depended on direction. As the directional semivariograms did not show anisotropy, i.e. differences in spatial dependence with directions, isotropic semivariogram models were chosen. Spherical, exponential and Gaussian models were evaluated and the model with the best fit was selected and parameters determined. These parameters are: (1) the range, the distance at which the semivariance ceases to increase, which represents the distance at which the spatial dependence between samples disappears; (2) the sill or the semivariance at which the semivariogram stabilizes, which equals the overall variance of the variable; and (3) the nugget variance or the ordinate value of the semivariogram at distance zero, which corresponds to the local variation occurring on scales finer than the sampling interval. Cross-validation was performed to check model validity (Isaaks and Srivastava, 1989). Once cross-validated, the model semivariograms were used in the kriging process to provide estimates of the indices at unsampled points. Ordinary kriging was performed on a regular grid of $1 \mathrm{~m} \times 1 \mathrm{~m}$. All the geostatistical/spatial analyses (semivariogram, cross-validation and kriging) were performed with the R package 'gstat' (Pebesma, 2004).

In order to ascertain the degree of spatial dependence among the data, we computed the spatial dependence index (SD), which expresses the nugget semivariance as a percentage of the total semivariance. If the SD index was lower than $25 \%$, the variable analyzed was considered strongly spatially dependent; if the ratio was between 25 and $75 \%$, the variable was considered moderately spatially dependent and if the index was greater than $75 \%$ the variable was considered weakly spatially dependent on the scale of observation (Cambardella et al., 1994).
In order to test the spatial stability of the weed seed bank diversity over time, we applied the bivariate generalization of the Cramér-von Mises nonparametric test for the difference between univariate spatial distributions (Syrjala, 1996).

\section{RESULTS AND DISCUSSION}

\subsection{Seed bank species}

The naturally occurring weed seed bank consisted of 30 grass and broad-leaved species. Lolium rigidum was the most abundant species in all three years. Polygonum aviculare and Papaver rhoeas were the most abundant dicots (Tab. I). According to Riba and Recasens (1990), L. rigidum and $P$. rhoeas are the most important grass and broad-leaved weeds, respectively, infesting winter cereals in northeastern Spain. The significant decrease in the seed bank size of Polygonum aviculare and Papaver rhoeas could be explained by the effectiveness of broad-leaved herbicide during the experiment, the negative effect of large established populations of Lolium rigidum and Avena sterilis (see the study of Blanco-Moreno et al., 2006 in the same experimental field) on the survival of emerged seedlings of $P$. aviculare and $P$. rhoeas, and the decay of the seed banks. Detailed studies on population dynamics taking into account the seed bank component are needed to gain further insights into the relative importance of the factors raised.

Weed seed bank densities and the relative abundance of each species in the soil varied from year to year but richness was relatively stable: a total of 23 species was recorded in 2001 and 2003, and 22 species in 2002 (Tab. I). Fourteen of the species $(47 \%)$ were recorded every year. Although herbicides may affect species richness because of their selectivity patterns, they generally affect relative abundance more than species composition (Derksen et al., 1995).

\subsection{Seed bank diversity and evenness}

The Shannon diversity index assessed for the entire field in 2001 was 1.50 (local values ranged between 0 and 1.74), decreasing to $0.55(0-1.33)$ in 2002 and rising to $0.81(0-1.55)$ in 2003. The evenness index was 0.48 in 2001 (local values between 0.24 and 1.00), dropping to $0.18(0.06-1.00)$ in 2002 and rising to $0.26(0.11-1.00)$ in 2003.

The diversity indices computed for the whole field were within the range of those reported for weed communities in cropping systems (Derksen et al., 1995; Légère et al., 2005). Low plant diversity indices and increased dominance of particular invasive weeds are typical of arable land as continuous disturbances (e.g. periodical plowing, herbicide spraying) and monoculture impoverish species pools in relation to undisturbed systems (Andreasen et al., 1996; Wilson W.L. et al., 2003). The seed bank was more diverse and even at the beginning of the experiment. Lack of narrow-leaved herbicide application in 2001 but control of broad-leaved weeds allowed grass weed seeds (Lolium rigidum and Avena sterilis) to shed onto 
Table I. Species of the weed seed bank, their density in seeds per $\mathrm{m}^{-2}$ with standard errors (SE) between brackets and their relative abundance (in\%) for each year.

\begin{tabular}{|c|c|c|c|c|c|c|}
\hline \multirow{2}{*}{ Weed species } & \multicolumn{2}{|c|}{2001} & \multicolumn{2}{|c|}{2002} & \multicolumn{2}{|c|}{2003} \\
\hline & Density (SE) & $\%$ & Density (SE) & $\%$ & Density (SE) & $\%$ \\
\hline Polygonum aviculare L. & $1414(111.3)$ & 30.4 & $722(66.2)$ & 9.8 & $335(27.3)$ & 8.6 \\
\hline Chenopodium album $\mathrm{L}$. & $155(18.2)$ & 3.3 & $16(4.0)$ & 0.2 & $27(4.9)$ & 0.7 \\
\hline Kickxia spuria (L.) Mill. & $105(11.7)$ & 2.3 & $30(4.9)$ & 0.4 & $38(6.4)$ & 1.0 \\
\hline Galium aparine $\mathrm{L}$. & $57(7.8)$ & 1.2 & $19(4.3)$ & 0.3 & $8.0(2.18)$ & 0.2 \\
\hline Convolvulus arvensis L. & $16(4.7)$ & 0.3 & $3.1(1.37)$ & $<0.1$ & $3.7(1.50)$ & 0.1 \\
\hline Medicago polymorpha $\mathrm{L}$. & $16(11.9)$ & 0.3 & $1.9(1.07)$ & $<0.1$ & $1.2(0.87)$ & $<0.1$ \\
\hline Anagallis arvensis L. & $11(2.8)$ & 0.2 & - & - & $1.2(0.87)$ & $<0.1$ \\
\hline Daucus carota $\mathrm{L}$. & $8.0(2.35)$ & 0.2 & - & - & - & - \\
\hline Atriplex patula $\mathrm{L}$. & $6.0(2.10)$ & 0.1 & $2.5(1.23)$ & $<0.1$ & $2.5(1.23)$ & 0.1 \\
\hline Veronica hederifolia L. & $3.7(1.50)$ & 0.1 & - & - & $0.6(0.62)$ & $<0.1$ \\
\hline Gagea villosa (M. Bieb.) Duby & $1.2(0.87)$ & $<0.1$ & $3.7(1.50)$ & 0.1 & $1.9(1.07)$ & $<0.1$ \\
\hline Sonchus oleraceus L. & $0.6(0.62)$ & $<0.1$ & $23(4.5)$ & 0.3 & $1.2(0.87)$ & $<0.1$ \\
\hline Lactuca serriola $\mathrm{L}$. & $0.6(0.62)$ & $<0.1$ & $0.6(0.62)$ & $<0.1$ & - & - \\
\hline Herniaria hirsuta L. & $0.6(0.62)$ & $<0.1$ & - & - & $0.6(0.62)$ & $<0.1$ \\
\hline Heliotropium europaeum L. & $0.6(0.62)$ & $<0.1$ & - & - & $1.2(0.87)$ & $<0.1$ \\
\hline Senecio vulgaris $\mathrm{L}$. & $0.6(0.62)$ & $<0.1$ & - & - & - & - \\
\hline Avena sterilis $\mathrm{L}$. & - & - & $20(5.8)$ & 0.3 & $147(20.2)$ & 3.8 \\
\hline Centaurium pulchellum (Swartz) Druce & - & - & $2.5(1.23)$ & $<0.1$ & $1.2(0.87)$ & $<0.1$ \\
\hline Linaria minor (L.) Desf. & - & - & $0.6(0.62)$ & $<0.1$ & $5.6(2.03)$ & 0.1 \\
\hline Reseda phyteuma $\mathrm{L}$. & - & - & $0.6(0.62)$ & $<0.1$ & - & - \\
\hline Matricaria chamomilla $\mathrm{L}$. & - & - & $0.6(0.62)$ & $<0.1$ & - & - \\
\hline Lepidium draba $\mathrm{L}$. & - & - & $0.6(0.62)$ & $<0.1$ & - & - \\
\hline
\end{tabular}

the soil and to occupy vacant niches, resulting in reduced diversity and evenness in 2002 . The herbicide treatment carried out in 2002 reduced the abundance of Lolium rigidum populations in 2003 (from $6405 \pm 285.7$ in 2002 to $3135 \pm 141.7$ seeds per $\mathrm{m}^{-2}$ in 2003), increasing the relative importance of the other species (although still at very low levels) and leading to an overall increase in diversity and evenness. The year-toyear variation in diversity and evenness in some sampling units differed from the value obtained for the entire field. Between 2001 and 2002, diversity increased in $7.5 \%$ of the sampling units (19 of 254), whereas the entire field index decreased. Between 2002 and 2003, diversity decreased in $28 \%$ of the sampling units (72 of 254 points), whereas the entire field index increased. Similar differences were observed in evenness; between 2001 and 2002, the entire field index decreased, but in $28 \%$ of the sampling units it increased and between 2002 and 2003, the entire field index increased, but in $39 \%$ of the sampling units it decreased.

\subsection{Spatial variation in species richness, diversity and evenness}

Spherical isotropic models gave the best fits to the experimental semivariograms of richness, diversity and evenness.
Nugget and sill parameters of semivariograms of species richness were 1.26 and 2.02, respectively, in 2001 and decreased to 1.16 and 1.95 in 2002 and to 0.91 and 1.41 in 2003; the range of spatial dependence decreased from $64.6 \mathrm{~m}$ in 2001 to $44.0 \mathrm{~m}$ in 2002 and to $29.2 \mathrm{~m}$ in 2003 (Tab. II). Nugget and sill parameters of semivariograms of diversity remained consistent from 2001 to 2003, with nugget ranging between 0.06 and 0.08 and sill ranging between 0.10 and 0.13 . Range values dropped every year (76.7 $\mathrm{m}$ in 2001, $46.9 \mathrm{~m}$ in 2002 and $45.1 \mathrm{~m}$ in 2003). The semivariograms of evenness ranged in nugget from 0.02 to 0.04 and in sill from 0.02 to 0.07 . Range values showed more variability between years, decreasing from $53.7 \mathrm{~m}$ in 2001 to $42.5 \mathrm{~m}$ in 2002 , but rising to 55.2 in 2003 .

In general, species richness, diversity and evenness were moderately spatially dependent (Tab. II). The spatial dependence of species richness was quite constant (SD was about $60 \%$ all years); conversely, the spatial dependence of diversity and evenness increased between 2001 and 2003 (SD diversity from $70 \%$ to $49 \%$ and SD evenness from $79 \%$ to $47 \%$ ), owing to an increase in the spatially structured variation in both indices.

Maps of species richness, diversity and evenness displayed patches of high values every year (Fig. 1). Comparison of distribution functions indicated that differences in diversity 


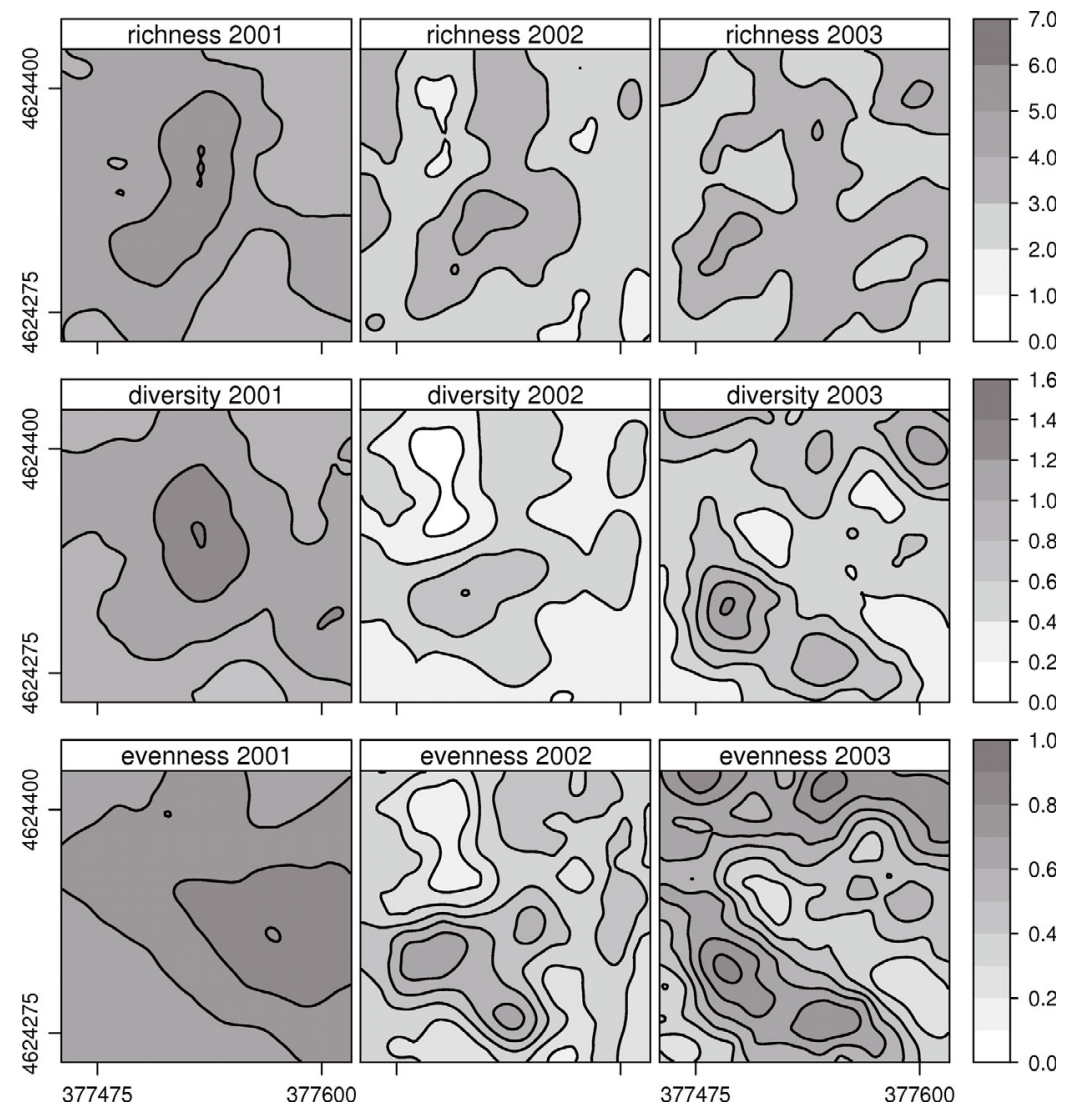

Figure 1. Contour maps of species richness, diversity and evenness of the seed bank in 2001, 2002 and 2003. Species richness, diversity and evenness were not homogeneous throughout the field, and their distributions were not constant over time. Diversity and evenness became more variable from 2001 to 2003, although the average values underwent oscillations. See more details in the text relating to the stability of their spatial distributions.

Table II. Estimated parameters from the model fitting of semivariograms for richness, diversity and evenness indices in 2001, 2002 and 2003. SD: Spatial Dependence index.

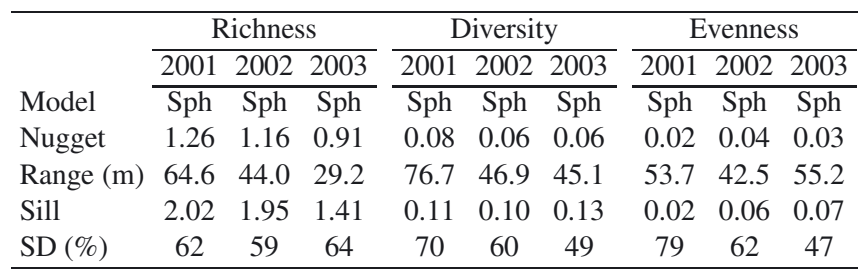

were statistically significant between $2001 / 2002(\psi=0.213$, $P=0.026)$ and between $2002 / 2003(\psi=0.237, P=0.002)$. Differences in evenness and richness distribution functions were not significant $(\psi=0.050, P=0.373 ; \psi=0.033$, $P=0.513$, respectively) between $2001 / 2002$ and significant ( $\psi=0.237, P=0.002 ; \psi=0.118, P=0.022$, respectively $)$ between 2002/2003. Areas of higher diversity corresponded with areas of higher evenness, especially in 2003 (Fig. 1). The higher spatial variation in diversity and evenness in 2003 is reflected in the semivariograms by a higher sill (Fig. 1) and in the maps by the greater number and the smaller extension of patches of high diversity and evenness (Fig. 1). The areas of maximum rate of diversity increase between 2002 and 2003 were those that had higher $A$. sterilis densities $\left(\mathrm{R}^{2}=0.16\right.$, slope: $0.06, P$-value $<0.0001$ ), and underwent the biggest reduction in L. rigidum densities $\left(\mathrm{R}^{2}=0.16\right.$, slope: -0.17 , $P$-value $<0.0001)$.

All semivariograms showed relatively high nugget effects, suggesting that small-scale processes such as predation, decay or microbial interaction may have greatly affected seed densities (or viability at least). The relatively homogeneous spatial distribution of diversity and evenness in 2001 did not persist. The amount of structured variability (sill-nugget) of diversity and evenness slightly increased over time, but the extent of this structured variability, given by the range, decreased. Reduction in the patch extension of some species such as Polygonum aviculare and Papaver rhoeas (data not shown) due to broadleaved control may have contributed to the increased patchiness of the indices, that is, the increase in the spatial structured diversity and evenness. Weed patches are reported to be stable in location under herbicide treatments (Barroso et al., 2004) but further research is necessary to evaluate the changes in the patches of high plant diversity over a longer period of time.

Spatial analysis of diversity can be a useful tool for identifying areas that may host biodiversity on a field scale, particularly when site-specific weed management aimed at 
maintaining a certain level of weed diversity in the field is developed. Furthermore, spatial analysis of the evenness of the weed seed bank community permits identification of field areas with a strong dominance of seeds from one or several harmful weeds and, accordingly, devising methods to control those specific areas in the context of precision agriculture. Finally, the use of spatial analysis for ecological indicators may have an extraordinary future on scales larger than the field. Knowledge of the weed diversity patterns on farm and regional scales may be a useful tool to understand the impact of agricultural practices on global biodiversity and to design agrienvironmental schemes (AES) to prevent biodiversity erosion.

\section{CONCLUSION}

Differences in diversity and evenness were observed within the field. The lack of narrow-leaved herbicide during the first year but the continuous broad-leaved herbicide treatment during the experiment increased grasses (Lolium rigidum and Avena sterilis) and reduced patch extension of some broadleaved species (Papaver rhoeas and Polygonum aviculare), increasing patchiness of diversity and evenness. Patches varied in location but persisted in all years. Weed diversity indices computed for the entire field showed a decrease in diversity and evenness in the second year and a slight increase during the third. However, these scores do not give information about the spatial structure of the community within the field. The spatial analysis of weed diversity identified weedy areas that contributed to maintaining biodiversity for the entire field. These analyses can identify areas for biodiversity conservation in cropland ecosystems and help to develop weed management practices that fully meet multifunctional EU agricultural aims.

Acknowledgements: The present work was funded by the Spanish Commission for Science and Technology (project AGL 1999-1125-C03-02) and partially supported by FEDER funds and the Spanish Ministry of Science and Innovation project (AGL2008-544).

\section{REFERENCES}

Andreasen C., Stryhn H., Streibig J.C. (1996) Decline of the flora in Danish arable fields, J. Appl. Ecol. 33, 619-626.

Barroso J., Fernández-Quintanilla C., Ruiz D., Hernaiz P., Rew L.J. (2004) Spatial stability of Avena sterilis ssp. ludoviciana populations under annual applications of low rates of imazametbenz, Weed Res. 44, 178-186.

Blanco-Moreno J.M., Chamorro L., Sans F.X. (2006) Spatial and temporal patterns of Lolium rigidum-Avena sterilis mixed populations in a cereal field, Weed. Res. 46, 207-218.

Bolòs O. de, Vigo J., Masalles R.M., Ninot J.M. (2005) Flora Manual dels Països Catalans, Editorial Pòrtic, Barcelona.

Cambardella C.A., Moorman T.B., Novak J.M., Parkin T.B., Karlen D.K., Turco R.F., Konopka A.E. (1994) Field-scale variability of soil properties in central Iowa soils, Soil Sci. Soc. Am. J. 58, 15011511.

Chamberlain D.E., Fuller R.J., Bunce R.G.H., Duckworth J.C., Shrubb M. (2000) Changes in the abundance of farmland birds in relation to the timing of agricultural intensification in England and Wales, J. Appl. Ecol. 37, 771-788.
Derksen D.A., Thomas A.G., Lafond G.P., Loeppky H.A., Swanton C.J. (1995) Impact of postemergence herbicides on weed community diversity within conservation-tillage systems, Weed Res. 35, 311320.

EEA (European Environment Agency) (2004) High nature value farmland, European Environment Agency report, No. 39, 32 p.

Firbank L.G. (1998) Biological Flora of the British Isles, No. 165, Agrostemma githago L., J. Ecol. 76, 1232-1246.

Gibson D.J. (2002) Methods in comparative plant population ecology, Oxford University Press, New York.

Hernández-Stefanoni L., Ponce-Hernández R. (2006) Mapping the spatial variability of plant diversity in a tropical forest: comparison of spatial interpolation methods, Environ. Monit. Assess. 117, 307-334.

Hyvönen J., Ketoja E., Salonen J. (2003a) Changes in abundance of weeds in spring cereal fields in Finland, Weed Res. 43, 348-356.

Hyvönen J., Ketoja E., Salonen J., Halli H., Tiainen J. (2003b) Weed species diversity and community composition in organic and conventional cropping of spring cereals, Agr. Ecosyst. Environ. 97, 131-149.

Isaaks E.H., Srivastava R.M. (1989) An Introduction to Applied Geostatistics, Oxford University Press, New York.

Légère A., Stevenson F.C., Benoit D.L. (2005) Diversity and assembly of weed communities: contrasting responses across cropping systems, Weed Res. 45, 303-315.

Marshall E.J.P, Brown V.K., Boatman N.D., Lutman P.J.W., Squire G.R., Ward L.K. (2003) The role of weeds in supporting biological diversity within crops fields, Weed Res. 43, 77-89.

Magurran A.E. (2004) Measuring biological diversity, Blackwell Science Ltd, Oxford.

Murphy S.D., Clements D.R., Belaoussoff S., Kevan P.G., Swanton C.J. (2006) Promotion of weed species diversity and reduction of weed seedbanks with conservation tillage and crop rotation, Weed Sci. 54, 69-77.

Pebesma E.J. (2004) Multivariable geostatistics in S: the gstat package, Comput. Geosci. 30, 683-691.

Podani J. (2006) With a machete through the jungle: some thoughts on community diversity, Acta Biotheor. 54, 125-131.

Riba F., Recasens J. (1990) Flora arvense de los cereales de invierno en Catalunya, in: Actas de la Reunión de la Sociedad Española de Malherbología, Ed. Sociedad Española de Malherbología, Madrid, pp. 239-246.

Robinson R.A., Sutherland W.J. (2002) Post-war changes in arable farming and biodiversity in Great Britain, J. Appl. Ecol. 39, 157-176.

Stoate C., Boatman N.D., Borralho R.J., Carvalho C.R., De Snoo G.R., Eden P. (2002) Ecological impacts of arable intensification in Europe, J. Environ. Manage. 63, 337-365.

Storkey J., Westbury D.B. (2007) Managing arable weeds for biodiversity, Pest. Manag. Sci. 63, 517-523.

Sutcliffe O.L., Kay Q.O.N. (2000) Changes in the arable flora of central southern England since the 1960s, Biol. Conserv. 93, 1-8.

Syrjala S.E. (1996) A statistical test for a difference between the spatial distributions of two populations, Ecology 77, 75-80.

Wang X., Hao Z., Ye J., Zhang J., Li B., Yao X. (2008) Spatial pattern of diversity in an old-growth temperate forest in Northeastern China, Acta Oecol. 33, 345-354.

Wilson W.L., Abernethy V.J., Murphy K.J. (2003) Prediction of plant diversity response to land-use change on Scottish agricultural land, Agr. Ecosyst. Environ. 94, 249-263.

Wilson P., King M. (2003) The biology of arable land plants, in: Arable land plants - a field guide, Ed. Hanway Press, London, pp. 42-47. 